Theme: Eletric Steelworks

\title{
ELECTRIC ARC FURNACE BEST OPERATION PRACTICES*
}

Nicolás Lugo ${ }^{1}$

\begin{abstract}
The electric steel industry has reached a level of maturity in its relative participation in the world's steel production. As the industry has grown and matured, EAF steel producers have participated in an ever more competitive market. This competition has led to a continuous search for lower cost alternatives for energy and input materials. Over the years, the Electric Steel Furnace community of operators has developed a variety of technological improvements geared to increasing EAF productivity. Operators have emphasized lowering operating costs and improving the quality of steels produced. Depending on market conditions, the EAF operators may run with different goals and priorities. In times of low demand, the goal may be to operate with an emphasis on cost and the goal of maximizing cost effective use of resources. When the market demand is high the goal may be to maximize EAF throughput. The objective of this work is to list some of the EAF operating best practices observed by our team in the electric arc furnace operations around the world. EAF operators can consider and possibly implement these practices depending on the specifics of each EAF operating reality.
\end{abstract}

Keywords: Productivity; Foaming slag; Tapping temperature; Hot heel.

1 Electrical and Mechanical Engineer, Customer Technical Service Engineer and TCO Coordinator, GrafTech International Inc., Parma, Ohio, USA.

* Technical contribution to the $45^{\text {th }}$ Steelmaking Seminar, May $25^{\text {th }}-28^{\text {th }}, 2014$, Porto Alegre, RS, Brazil. 


\section{INTRODUCTION}

Electric Arc Furnace steel making (EAF) was introduced at the end of the $19^{\text {th }}$ century. These technologies and equipment have grown to become a process used around the world for the production and processing of steel. According to published steel production records [1] for 2012, the level of EAF steel (Figure 1) reached $455,000 \mathrm{kt}$, the highest yearly production ever; in 2012, the EAF steel represents $29 \%$ of total steel production around the world and that value has been very steady over the last three years.

Most of the industrialized countries are gradually moving towards a more extensive use of EAF technology for steel production. Conventional methods of steel production (BF/LD Furnaces) have been pressured by many factors in the market but each region of the world has its own unique set of dynamics. Stringent emissions regulations in the coke processing side of that process is an example of such forces. Amongst the biggest challenges that the production of steel via EAF faces today are the cost of the raw materials and the costs of energy and other inputs. These challenges are exacerbated in a depressed market. The combined effect of these factors determines the current state of affairs: a continuous ongoing search for more cost effective ways to run the EAF operations. The usual areas that capture the operator's attention are linked to the optimum use of electrical energy, refractory materials and graphite electrode consumption.

An important point is that when the market demand is high, some of these indicators may yield the highest level of importance to furnace throughput and productivity. Conversely, in times of low demand the emphasis may revert to fully controlling the operating costs.

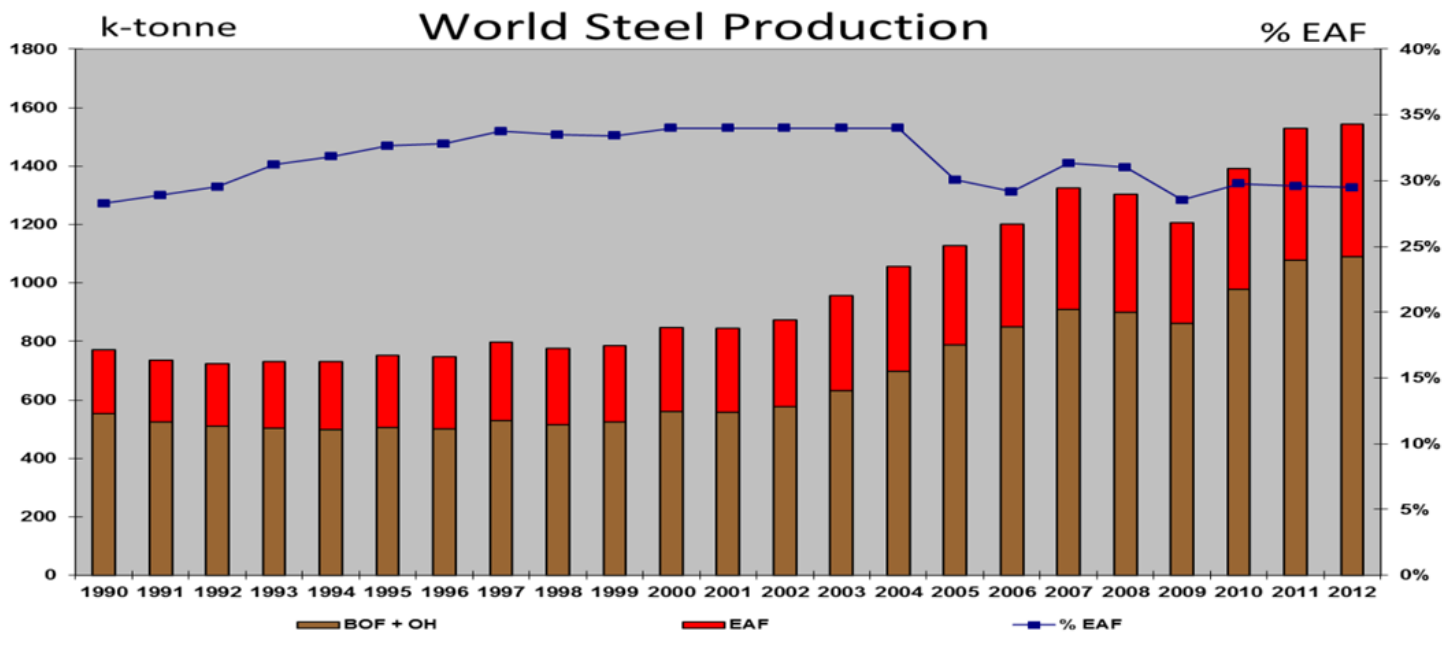

Figure 1. World Steel Production (source: IISI).

\section{OUR REFERENCE POINT}

GrafTech's EAF benchmark database contains over 1000 furnaces worth of EAF operational data from operations around the world. In the preparation of this paper we are using the same criteria and furnaces as those utilized by our colleague Wayne Adams for the preparation of his yearly presentation of the EAF Benchmarking at the AIST's EAF yearly training seminar [2]. The furnaces included in our study are those that place amongst the best operations in the world in terms of

* Technical contribution to the $45^{\text {th }}$ Steelmaking Seminar, May $25^{\text {th }}-28^{\text {th }}, 2014$, Porto Alegre, RS, Brazil. 
productivity. These EAF's have the operational indicators that have defined good EAF operations around the world. All furnaces included utilize $100 \%$ scrap as metallic charge and are devoted to the production of carbon steel.

The idea of including only scrap-based operations is to avoid possible confusion. Operational parameters can be directly affected by the type of charge material (i.e. hot metal, DRI, Etc.) Charge material affects total energy consumption depending on the percent of scrap substitution by either of these alternate iron unit sources.

Based on the previous, a total of 160 EAF operations were utilized for this study. The sub-types of EAF are represented by conventional AC furnaces (48\%), High Reactance AC (35\%) and DC furnaces (17\%) from Europe, America and Asia.

\section{ELECTRIC SPECIFIC CONSUMPTION - THE DEPARTING POINT}

Adams et al. [3] reported that the EAF's total energy consumption is approximately $580 \mathrm{kWh} / \mathrm{t}$. This figure includes many good operations around the world and is related to the amount of energy required to process $100 \%$ scrap at room temperature. The same source cites several factors that may influence EAF energy consumption. These include; the type and composition of the charge materials, efficiency in the use of alternate energy sources, foaming slag practice efficiency and power program and regulation performance.

Other factors that would exert direct influence over total energy consumption is the possible use of EAF fume gas as an alternate source of heat for the EAF as is the case for some shaft type furnaces and Tenova's Consteel ${ }^{\circledR}$ EAF process. The energetic advantage of this type of furnaces has already been covered in previous works.

The graph displayed below (Figure 2) shows the relationship of electrical energy consumption on the EAF as a function of oxygen consumption [4]. Obviously, the greater the efficient consumption of oxygen, the lower the electrical energy consumption would be. From the regression analysis on the same chart we can also infer that the average oxygen electrical energy equivalence is approximately $3.6 \mathrm{kWh} / \mathrm{t}$. In other words; the average efficiency of oxygen usage is approximately $70 \%$ of its theoretical value.

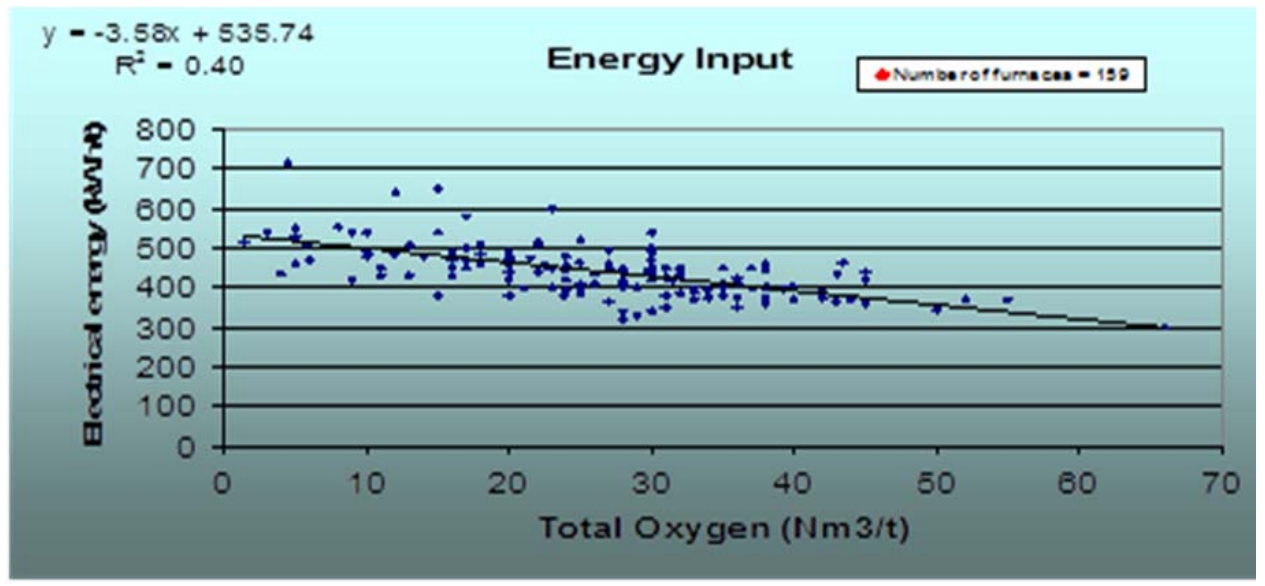

Figure 2. Specific Electrical Energy vs. Oxygen Consumption.

Table 1 displays some of the main operational parameters of the EAF operations in the chart in Figure 2. To define the basis for our study, we produced a regression line that would split the furnaces above and below this line. The better EAF operations

* Technical contribution to the $45^{\text {th }}$ Steelmaking Seminar, May $25^{\text {th }}-28^{\text {th }}, 2014$, Porto Alegre, RS, Brazil. 
are below the line and the EAF's with opportunities for improvement are above the line. The main operating parameters that define these operations will be covered later in this work.

At a glance, the group of EAF's below the line (better operations) display lower energy consumption, better use of time (power-on and power-off) and better operating parameters in general. An important part of this study is an attempt to identify those parameters that best define a "better" operation. We performed a TTest on the parameters and found that, from all the EAF parameters considered, only a few actually reported high values in the T-Test. This confirmed that a small subset of parameters correlate with the "better" operations and are statistically different. The EAF parameters that scored high in our test were: tapping temperature, Tap-to-Tap time, the number of baskets per heat, the Power-on time, EAF slag additions (slag practice) and the hot heel practice.

Furnace size, melting power level (MW) and oxygen capacity did not report high level of statistical significance in our study.

Table 1. TTest of EAF main operating parameters

\begin{tabular}{|c|c|c|c|c|c|c|c|c|c|}
\hline \multicolumn{10}{|c|}{ T TEST with $95 \%$ confidence level } \\
\hline & \multicolumn{4}{|c|}{ Population 1} & \multicolumn{3}{|c|}{ Population 2} & & \\
\hline & & \multicolumn{3}{|c|}{$\begin{array}{l}\text { Above line (high } \\
\text { energy) }\end{array}$} & \multicolumn{3}{|c|}{$\begin{array}{l}\text { Below line (low } \\
\text { energy) }\end{array}$} & \multirow[b]{2}{*}{$\mathrm{U}$} & \multirow[b]{2}{*}{ Significa } \\
\hline Parameter & Unit & $\mathrm{N}$ & Avg & Std & $\mathrm{N}$ & Avg & Std & & \\
\hline Tap Temperature & ${ }^{\circ} \mathrm{C}$ & 59 & 1656 & 30.7 & \multirow{2}{*}{$\begin{array}{l}6 \\
8\end{array}$} & \multirow{6}{*}{$\begin{array}{l}1633 \\
74.3 \\
2.4 \\
39.4 \\
34 \\
13.4\end{array}$} & \multirow{6}{*}{$\begin{array}{l}25.8 \\
29.1 \\
0.8 \\
26.1 \\
8.8 \\
8.6\end{array}$} & \multirow{6}{*}{$\begin{array}{l}4.3 \\
3.6 \\
2.8 \\
2.4 \\
2.1 \\
2.1\end{array}$} & Yes \\
\hline Tap-To-Tap Time & $\min$ & 74 & 97.6 & 47.6 & & & & & Yes \\
\hline Number of baskets & \# & 64 & 2.8 & 0.8 & 6 & & & & Yes \\
\hline Power On Time & $\min$ & 72 & 51.8 & 34.0 & 7 & & & & Yes \\
\hline Total slaq add & $\mathrm{kg} / \mathrm{t}$ & 34 & 42 & 19.5 & 3 & & & & Yes \\
\hline Liquid heel & $T$ & 38 & 10.3 & 4.4 & 4 & & & & Yes \\
\hline O2 flow & $\mathrm{Nm}^{3}$ & 60 & 1746 & 1403 & 7 & \multirow{9}{*}{$\begin{array}{l}2191 \\
5.5 \\
49.9 \\
372 . \\
767 . \\
89 \\
307 \\
3556 \\
5.8\end{array}$} & \multirow{9}{*}{$\begin{array}{l}1450 \\
1.0 \\
20.4 \\
119.1 \\
235.2 \\
39.1 \\
85.2 \\
1764.0 \\
1.2\end{array}$} & \multirow{9}{*}{$\begin{array}{l}1.8 \\
1.6 \\
1.6 \\
1.5 \\
1.3 \\
1.2 \\
1.1 \\
1.1 \\
0.5\end{array}$} & No \\
\hline Lenqth under electrode & $\mathrm{m}$ & 45 & 5.2 & 0.7 & 4 & & & & No \\
\hline Melting Power & MW & 61 & 44.3 & 17.8 & 6 & & & & No \\
\hline Max Varc AC only & $\mathrm{V}$ & 35 & 328. & 104.2 & 3 & & & & No \\
\hline Vtap max used & V & 59 & 712. & 214.4 & 6 & & & & No \\
\hline Tap weight & $T$ & 75 & 82 & 30.6 & 8 & & & & No \\
\hline Avq Varc AC only & $\mathrm{V}$ & 57 & 287. & 84.3 & 5 & & & & No \\
\hline Max 02 flow & $\mathrm{Nm}^{3}$ & 12 & 2867 & 1456.0 & 1 & & & & No \\
\hline Shell diameter & $\mathbf{m}$ & 67 & 5.7 & 1.0 & 8 & & & & No \\
\hline Reactance imbalance & $\%$ & 24 & 10.5 & 6.4 & 2 & 10.2 & 8.4 & 0.1 & No \\
\hline
\end{tabular}

\section{EAF BEST PRACTICES}

The groups of operating parameters that correlate with the best EAF operations in the world were grouped together and called the "EAF Best Practices". The goal is to take each of the parameters (displayed in the Table 1) and develop or explain the methodology or process that these "first tier" operations follow. These practices are shown to be important in distinguishing the best operations in the world. The ultimate goal is to stir a dialog in consideration of those operational practices. Ultimately, the "EAF Best Practices" could be applicable in other operations depending on each EAF operation's reality.

\footnotetext{
* Technical contribution to the $45^{\text {th }}$ Steelmaking Seminar, May $25^{\text {th }}-28^{\text {th }}, 2014$, Porto Alegre, RS, Brazil.
} 


\subsection{Tapping Temperature}

According to published literature the energy to heat one tonne of steel from room temperature to tapping temperature $\left(1600^{\circ} \mathrm{C}\right)$ is $375 \mathrm{kWh}$ [5]. Obviously this figure was obtained in a laboratory and in "real life" these figures are never achieved. A variety of factors including thermal losses and impurities in the charge materials separate the EAF operational reality from theoretical values

Continuing with the same source, the amount of energy required to elevate the temperature of one tonne of steel from $1540^{\circ} \mathrm{C}$ to $1600^{\circ} \mathrm{C}$ is $14.4 \mathrm{kWh}$, this fact reinforces the great importance of controlling the tapping temperature to its minimum required as a practical way to maintain the EAF operating cost control.

The additional cost in electrical energy consumption for tapping $60^{\circ} \mathrm{C}$ hotter in a $100 \mathrm{t}$ EAF could be between $\$ 50$ and $\$ 100$, depending upon energy costs. Tapping $60^{\circ} \mathrm{C}$ too hot can add costs of up to $\$ 1 / \mathrm{t}$. This added cost only refers to the electrical energy needed it also takes significant process time to elevate the temperature, and with that, the productivity of the EAF will decrease.

The time required to increase the bath temperature by $60^{\circ} \mathrm{C}$ would be between one and two minutes of power-on, depending on the operating power and the thermal efficiency of the operation. The histogram displayed below shows an ample gamma of specific heat in

$\left(\mathrm{kWh} / \mathrm{t}-{ }^{\circ} \mathrm{C}\right)$ for a 120t EAF installation. Of note is the wide distribution for this indicator. The range is from 0.14 to $0.5 \mathrm{kWh} / \mathrm{t}-{ }^{\circ} \mathrm{C}$ with an average of $0.36 \mathrm{kWh} / \mathrm{t}-{ }^{\circ} \mathrm{C}$. Of interest is the histogram's distribution; is not normal and includes a right hand side "tail" extending far more than the left hand side "tail". The possible explanation is that different practices for foaming slag, oxygen inputs and metallurgical balance have a significant effect on this parameter.

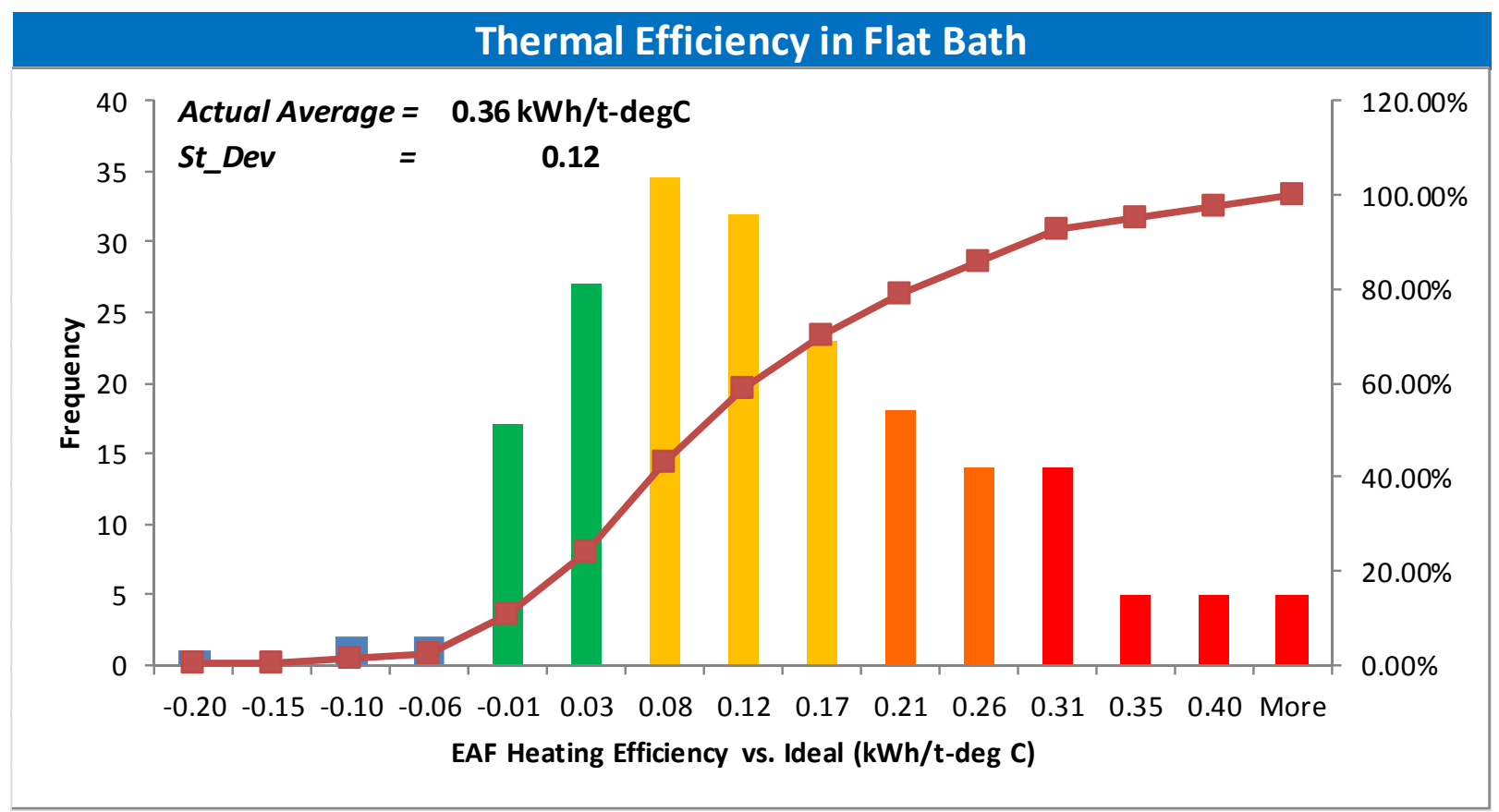

Figure 3. Heating efficiency in a 129t EAF.

In another case, our colleagues reported savings of up to $7 \mathrm{kWh} / \mathrm{t}$ achieved at a melt shop by controlling the tap temperature. This was a function of controlling the thermal

* Technical contribution to the $45^{\text {th }}$ Steelmaking Seminar, May $25^{\text {th }}-28^{\text {th }}, 2014$, Porto Alegre, RS, Brazil. 
losses in the ladle after tapping and the expected wait time between LMF and Continuous Casting processes [6].

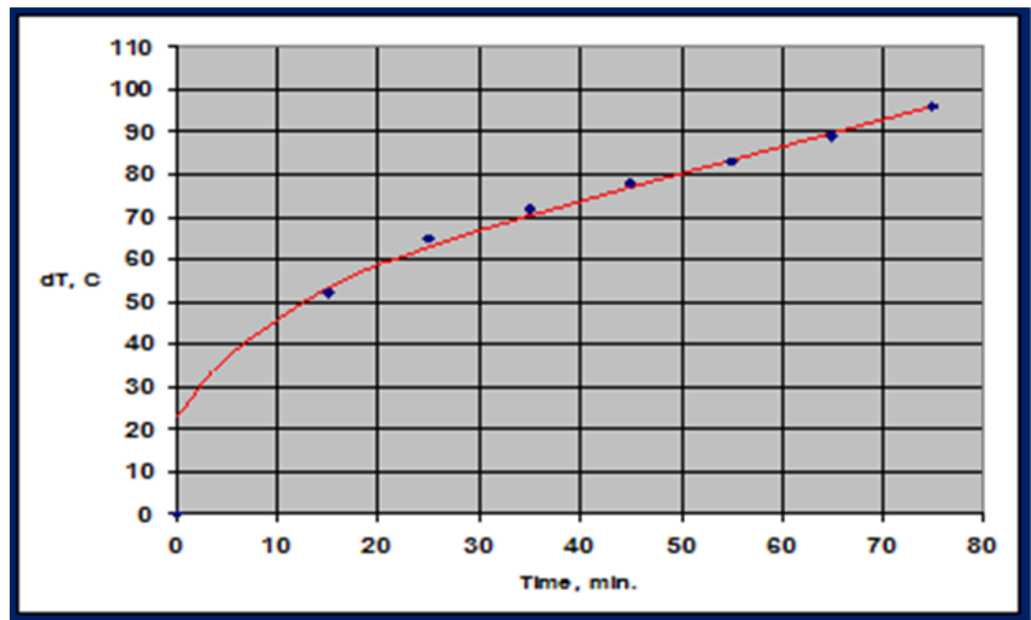

Figure 4. Thermal losses vs. wait time in ladle.

\subsection{Time Utilization (Power-On, Tap-To-Tap)}

The time utilization efficiency is without a doubt one factors with high influence in the EAF's energy consumption - The longer the heat time, the larger the EAF thermal losses.

\subsection{Tap-To-Tap Time}

In general, we correlate high productivity melt shops with short tap-to-tap times (60 min and below as the benchmark). Over the last several years there have been new furnace installations with increasing heat sizes. This marks a major departure from the conventional $100-150 \mathrm{t}$ furnaces installed during the decades of the 90's and 2000's. In terms of TPH these large furnaces are well within the pre-requisites to be included in our EAF Benchmarking database since their productivity surpasses the $100 \mathrm{t} / \mathrm{h}$ minimum required

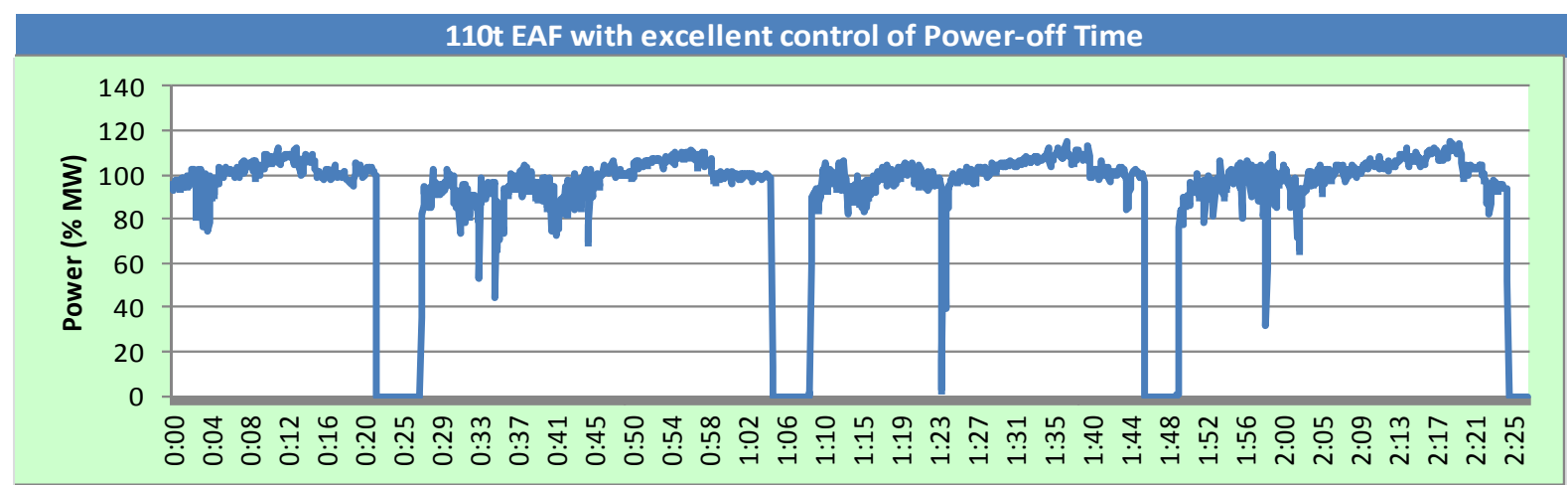

Figure 5. Heat profiles with very low Power-Off Time (110 t EAF).

In the table shown above, the group of furnaces with "improvement opportunities" averaged 98 minutes of TTT. The group of furnaces below the trend-line (better operations) averaged 74 minutes of TTT. Worthy of mentioning is the fact that, after tapping temperature, this factor scored the highest significance value in our T-Test.

* Technical contribution to the $45^{\text {th }}$ Steelmaking Seminar, May $25^{\text {th }}-28^{\text {th }}, 2014$, Porto Alegre, RS, Brazil. 
The factors with high influence in determining the TTT in a furnace can be: ratio of Heat Size to Average Operating Power, scrap quality and composition, the use of chemical energy, efficiency of the use of time (\% TU) and number of baskets per heat.

\subsection{Power-On Time (POT)}

The main factor determining the extent of time needed to melt a heat would be the relationship between the heat-size and the power available to for the melt down process (both electrical and chemical). Nowadays it is quite common to read about EAF operations with POT levels around 29 to 33 minutes per heat in furnaces with heat sizes from 90 to $150 \mathrm{t}$. These furnaces can be equipped with transformers ranging from 80 to 140 MVA. Some of the fastest furnaces have an average poweron time of 23 minutes and a rate of production of approximately $200 \mathrm{TPH}$. In other words, there are some furnaces charging 100\% cold scrap, tapping over one million tons per year equipped with $90 \mathrm{t}$ furnaces and 90 MVA transformers.

\subsection{Power-Off Time}

GrafTech' S EAF Benchmarking establishes an average Power-off time at 15 minutes per heat. This value is very similar for all types of electric furnaces (i.e. conventional AC, High Reactance, DC EAFs). A point worthy of note is that there are some EAF operations that report Power-off times in the order of 4 to 8 minutes per heat. As an example the Figure 5 displays a series of heats from a world class operation in which the power-off time is approximately five minutes between heats.

At this point we make note that the Power-off parameter mentioned here does not include the scheduled down days for EAF repairs, mold changes or off-peak hours. The types of delays or Power-off time we include here are related to the operation of the EAF. These delays include adding electrodes, back-charging, turnaround time, and non-scheduled maintenance delays

In some cases we have documented furnaces running for long periods of time with only two minute power-off time in furnaces equipped with twin shell technology and single charge practice. In the case of conventional single shell furnaces, some of the best operations score 6 to 9 power-off minutes per heat. The Table 2 displays one month worth of EAF operation of a tall shell, single charge per heat EAF. This $110 \mathrm{t}$ furnace equipped with a 90 MVA transformer produces over one million ton per year of finished product.

Table 2. Typical operational figures for a $1 \mathrm{Mt} / \mathrm{annum} \mathrm{EAF}$

\begin{tabular}{ccccc}
\multicolumn{5}{c}{ Benchmark EAF Performance } \\
MVA & TTT & POT & P-off & T/h \\
90 & 46 & 37 & 9 & 150
\end{tabular}

\subsection{Number of Baskets Per Heat}

As mentioned earlier on this paper, the number of charges per heat has a great level of significance in determining the "world class" EAF operation. In our study, the furnaces with higher energy consumption (Figure 1) averaged 2.8 baskets per heat while the lower energy consumption EAFs scored 2.4 scrap baskets per heat in

* Technical contribution to the $45^{\text {th }}$ Steelmaking Seminar, May $25^{\text {th }}-28^{\text {th }}, 2014$, Porto Alegre, RS, Brazil. 
average. In general, it has been established that each time the roof opens, the time lost is not only related to the actual elapsed during the back-charge but also, with the time required to compensate (with energy) for the temperature lost during that same time. In a case [7] reported in 2009 related to the conversion of an EAF from two bucket charge to single bucket charging, the authors reported expected savings on energy consumption associated with a higher melting efficiency as well as reduction on Power-on time. Table 3 shows some of the savings after the revamping of one EAF enabling the single charging practice.

Table 3. EAF improvements after shell modifications to single charge practice

\begin{tabular}{|r|c|}
\hline Parameter & After $(\%)$ \\
\hline Ht. Size (Ton) & +0.7 \\
\hline Power-on & -17.1 \\
\hline Energy Cons. & -5.3 \\
\hline Oxygen Cons. & +6.3 \\
\hline Avg. Power & -2.1 \\
\hline Melting Speed & +15.1 \\
\hline EAF output & +10 \\
\hline
\end{tabular}

\subsection{Hot Heel Practice}

With the introduction of the EBT design in furnaces the hot heel practice started to be used by many steelmakers. The idea was to use it as a "catalyzer" for the melting process in the following heat. As a rule of thumb the amount of metal left in the EAF as hot heel varies from 10 to $20 \%$ of the actual heat size (i.e. 10 to $20 \mathrm{t}$ for a $100 \mathrm{t}$ EAF). The exception to this would be the CONSTEEL $®$ furnaces. In this case the hot heel size could be up to $50 \%$ of the actual heat size [8].

Recent works [6] on this subject reported savings of $11 \%$ in energy consumption in a melt shop that increased the hot heel size from $6 \%$ to $25 \%$. Along with the savings on energy consumption, this work also cited additional advantages:

- Reduction of Power-on Time

- Reduction of slag carryover into the ladle

- Increased arc stability

\subsection{Foaming Slag Practice}

There are plenty of technical papers quoting the benefits of a good foaming slag practice; Uyén $(t)$ presented an impressive work in his papers related to the Sealed Furnace Practice [9]. Pretorius [10] also made a great contribution to the steelmaking community with his work helping define foaming slag's characteristics. In general, the benefit of a good foaming slag practice has been quantified at approximately $20 \mathrm{kWh} / \mathrm{t}$. In previous work we have presented the results of a $145 \mathrm{t}$ EAF in terms of electrical energy consumption as a function of foaming slag quality. The following graph displays the results of over 800 heats.

* Technical contribution to the $45^{\text {th }}$ Steelmaking Seminar, May $25^{\text {th }}-28^{\text {th }}, 2014$, Porto Alegre, RS, Brazil. 

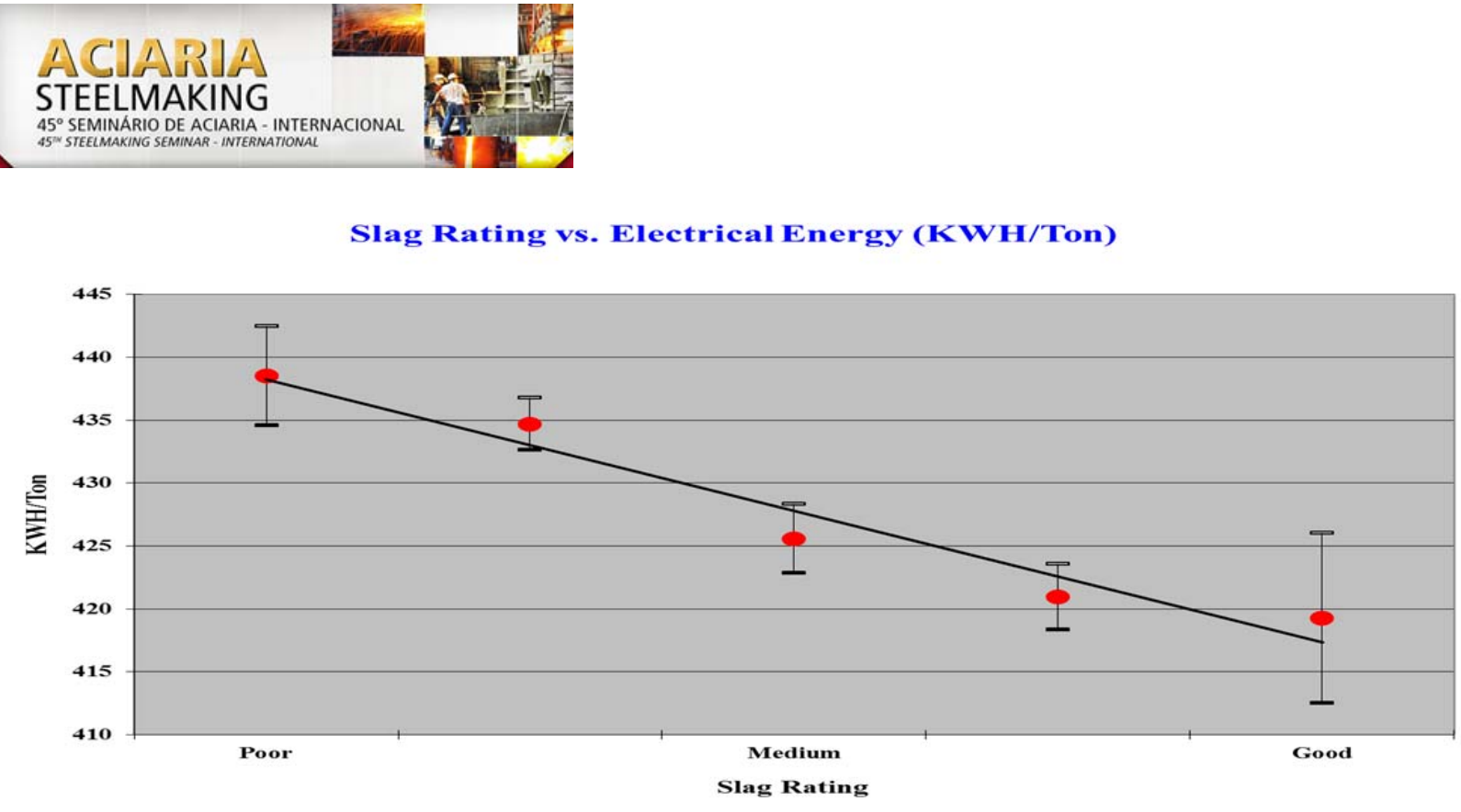

Figure 6. Electrical energy consumption vs. Slag Rating.

In a different exercise a comparison was made of approximately 160 furnaces. The foaming slag qualifier produced a difference in total energy consumption of $34 \mathrm{kWh} / \mathrm{t}$ between the furnaces below the regression line in our starting chart (Figure 2) and the furnaces with "greater potential for improvement". In a 100t/80MVA EAF type of operation, the Power-on Time required to overcome this excess energy would be approximately 4 minutes per heat!

\section{OTHER OPERATIONAL INDICATORS IN THE EAF}

\subsection{The Use of Power}

The average melting power did not score high in the T-test and was then determined to have a lower correlation with a "better" operation. Yet the efficient use of available power, along with supplementary chemical energy can have a significant effect in determining the EAF's operational characteristics. These two items are clearly related to the Power-on Time in the EAF operation within the practical limits dictated by the specific metallurgical practice (foaming slag practice and charge and injected carbon practices).

\subsection{Hot Metal}

The use of hot metal as part total charge practice could also greatly reduce the Power-on Time in an EAF operation. In some applications the amount of hot metal charged amounts up to $40 \%$ of the total metallic charge. In our EAF Database, the average proportion charged by these furnaces was $36 \%$. The average energy savings associated with this practice was approximately $3.9 \mathrm{kWh} / \mathrm{t}$ per each percent point of scrap substitution.

\section{CONCLUSION}

The best operating practices in the EAF operation are the real definers of the level of success of the operation. Once the EAF's design characteristics i.e. heat size, transformer capacity, scrap characteristics have been considered, the efficiency of time utilization is the most important and influential factor in the successful EAF

* Technical contribution to the $45^{\text {th }}$ Steelmaking Seminar, May $25^{\text {th }}-28^{\text {th }}, 2014$, Porto Alegre, RS, Brazil. 
Operation. The management of the power-off time is a great challenge but can be the key factor in determining the successful and profit of an EAF operation.

Controlling the tapping temperature can depend on the downstream process requirements (LMF, continuous caster) but can still mean substantial savings in the EAF operation. Eliminating excess energy consumption due to higher-than-needed tapping temperatures as well as by reducing the power-on time associated with these longer-than-needed heat times are significant issues in cost control.

Lastly, the successful increase of the hot heel amount from originally $6 \%$ up to 18 $25 \%$ demonstrated a beneficial effect in terms of energy consumption, arc stability and electrode savings.

\section{REFERENCES}

1 IISI - International Iron and Steel Institute. Worldsteel production statistics. Brussels; IISI; 2013.

2 Adams W. Benchmarking the modern melt shop. AIST's modern electric furnace steelmaking - A practical training seminar and the specialty steelmaking training (yearly event). Birmingham, AL, USA; 2013.

3 Adams W, Alameddine S, Bowman B, Lugo N, Peage S, Stafford P. Factors influencing the total energy consumption in arc furnaces. In: ISS. 2001 Electric Furnace Conference Proceedings; 2001; Phoenix, USA. ISS: Iron and Steel Society; 2001. P. 691

4 Potey D. Benchmarking the energy consumption in modern arc furnaces. In: Graftech South Africa Technical Seminar; $6^{\text {th }}$ Nov. 2008;

5 Fruehan RJ, Fortini O, Paxton HW, Brindle R. Theoretical minimum energies to produce steel for selected conditions. Pittsburg: Carnegie Mellon University;2000.

6 Alameddine S, Bowman B, Paege S, Stafford P. Innovative solutions for lowering the conversion cost of steel in arc furnaces. In: AIM Conference; 2009; Milano, Italy. 2009.

7 Gerhan R, Krotov Y, Lugo N. Secondary system mechanical resonance in new tall-shell SDI-Butler arc furnaces: detection and solutions. In: AIST Conference Proceedings; 2009 Pittsburg, USA. Warrendale: AIST; 2009.

8 Memoli F, Jones JAT, Picciolo F. How changes in scrap mix affect the Operation of Consteel囚 EAF. In: AIST Conference Proceedings; 2013; Pittsburg, USA. Warrendale: AIST; 2013.

9 Uyén $\mathrm{J}(\mathrm{t})$. Continuous feeding of shredded scrap using closed door process. In: ABM. $36^{\circ}$ Seminário de Aciaria - Internacional; 2006; Porto Alegre, Brasil. São Paulo: ABM; 2006.

10 Pretorious E. Fundamentals of EAF and ladle slags and ladle refining principles. Available at: http://etech.Iwbref.com.

* Technical contribution to the $45^{\text {th }}$ Steelmaking Seminar, May $25^{\text {th }}-28^{\text {th }}, 2014$, Porto Alegre, RS, Brazil. 